\title{
DETECÇÃO DE PLANTIOS DE CANNABIS SATIVA NO SEMIÁRIDO PERNAMBUCANO A PARTIR DA ANÁLISE \\ DAS ANOMALIAS DE DINÂMICA TEMPORAL DOS ÍNDICES DE VEGETAÇÃO DERIVADOS DO SATÉLITE SPOT-5 HRG
}

Detection of Cannabis sativa plantations in the semi-arid region of Pernambuco State in Brazil based on the analysis of temporal dynamic anomalies of vegetation index derived from SPOT-5 HRG satellite data

\author{
ALESSANDRA LISITA ${ }^{1}$ \\ EDSON EYJI SANO ${ }^{2}$ \\ LAURENT DURIEUX ${ }^{3}$ \\ ${ }^{1}$ Departamento de Polícia Federal \\ Instituto Nacional de Criminalística \\ Área dePerícias de Meio Ambiente \\ SAIS Quadra 07, lote 23, CEP: 70.610-200, Brasília/DF \\ ${ }^{2}$ Embrapa Cerrados \\ BR-020 km 18 CEP: 73301-970 Planaltina/DF \\ ${ }^{3}$ Institut de Recherche pour le Développement (IRD) \\ UMR 228 ESPACE-DEV \\ Maison de la Télédétection, 500 rue JF Breton, 34093 Montpellier Cedex 05, France \\ E-mail: alessandra.al@dpf.gov.br; edson.sano@embrapa.br; laurent.durieux@ird.fr
}

\section{RESUMO}

A Cannabis sativa é a droga ilícita mais consumida no mundo, à frente de anfetaminas, cocaína e opiáceos. No Brasil, uma das estratégias de redução da oferta dessa droga é a realização de operações de erradicação de cultivos. Nessas operações, os sítios são identificados visualmente por policiais experientes durante sobrevoos com helicópteros. Este estudo analisa o emprego do NDVI (índice de vegetação por diferença normalizada) derivado de séries temporais do satélite SPOT-5 HRG (High Resolution Geometric) na detecção de plantios de Cannabis em meio às fitofisionomias de Caatinga do sertão pernambucano. Valores absolutos e 
multitemporais do NDVI de dois sítios utilizados para o plantio de Cannabis e da vegetação natural circundante foram analisados com vistas à prospecção de anomalias relacionadas à presença dos plantios. Os resultados indicaram forte sazonalidade das fitofisionomias de Caatinga e padrões irregulares dos plantios de Cannabis sativa. Em alguns casos, os plantios de Cannabis apresentaram taxas de crescimento superiores às áreas de vegetação natural, induzidas pelo suprimento de água de irrigação e adubação das plantas; em outros, quedas abruptas de NDVI decorrentes de operações de preparo do solo, colheita ou erradicação. A análise da dinâmica do NDVI permitiu detectar plantios de Cannabis em séries temporais do SPOT-5 HRG.

Palavras-chave: Sensoriamento Remoto; NDVI; Drogas Ilícitas.

\begin{abstract}
Cannabis sativa is the most highly demanded illegal drug in the world, even more than amphetamines, cocaine and opiates. In Brazil, one of the strategies to reduce its consumption is the identification and destruction of cultivation. Plantations are identified visually by experienced Brazilian Federal Police agents using helicopters. This study analyzed the potential of the NDVI (Normalized Difference Vegetation Index) derived from temporal series of the SPOT-5 HRG (High Resolution Geometric) images to detect plantations of Cannabis surrounded by the Caatinga vegetation in the semi-arid region of Pernambuco State. Absolute values and multitemporal series of NDVI from two sites used to plant Cannabis and from surrounding natural vegetation were analyzed to find anomalies related to the presence of such plantations. Results showed a strong seasonality of Caatinga phytophysiognomies and heterogeneous spectral pattern of Cannabis sativa. In some cases, Cannabis plantations presented growing patterns higher than the Caatinga vegetation, as a consequence of water and fertilizer supplies; in other, an abrupt decrease of NDVI values, as a consequence of field management practices soil preparation and harvesting - or destruction. The analysis of dynamics of NDVI allowed detecting Cannabis cultivations from temporal series of SPOT-5 HRG.
\end{abstract}

Keywords: Remote Sensing; NDVI; Illicit Drugs.

\title{
1. INTRODUÇÃO
}

Embora o cultivo de Cannabis tivesse sido relatado por 172 países no período de 1997 a 2007 (UNODC, 2008), devido a dificuldades em estimar a extensão dessa cultura ilícita, apenas 21 deles forneceram alguma informação sobre a área cultivada em 2007. Os recentes avanços na tecnologia de satélites, com crescente disponibilidade de dados de sensores remotos de alta resolução espacial e temporal, favorecem o emprego desses dados na produção de informações de inteligência espacial para as agências governamentais envolvidas na política anti-drogas. Entretanto, a Cannabis sativa apresenta comportamento espectral típico das plantas verdes (DAUGHTRY \& WALTHALL, 1998; WALTHALL et al., 2006) e o seu 
plantio geralmente ocorre em meio à vegetação natural (LISITA, 2011) dificultando a detecção por sensoriamento remoto. Por outro lado, o incremento da atividade fotossintética das plantas de Cannabis sativa, induzida pelo emprego de técnicas de manejo como irrigação e fertilização, pode resultar em diferenças na dinâmica de crescimento desses plantios, em relação à vegetação circundante, favorecendo a detecção dessas feições em séries temporais de imagens de satélite.

Índices de vegetação têm sido usados em estudos de dinâmica da vegetação e monitoramento de safras (EL HAJJ et al., 2008). O Índice de Vegetação por Diferença Normalizada (NDVI), definido como a diferença entre as reflectâncias nas faixas espectrais do infravermelho próximo e do vermelho dividida pela sua soma (TUCKER, 1979), é considerado particularmente útil para o monitoramento de atividade fotossintética e comparações de variações sazonais e interanuais (RATANA et al., 2005; PONZONI \& SHIMABUKURO, 2007), tendo sido usado também para mapear lavouras irrigadas no sertão nordestino (CAMILO et al., 2010). Este estudo analisa o emprego do NDVI derivado de séries temporais do satélite SPOT-5 HRG (High Resolution Geometric) na detecção de plantios de Cannabis sativa em meio às fitofisionomias de Caatinga no sertão pernambucano.

\section{MATERIAIS E MÉTODOS}

\section{1 Área de Estudo}

A área de estudo localiza-se no estado de Pernambuco, na região conhecida como sertão central, na bacia do rio São Francisco (Figura 1). Trata-se de uma das áreas mais críticas do país no que se refere ao cultivo ilícito de Cannabis sativa, sendo que trabalhos pioneiros de emprego de sensores remotos para detecção de plantios ilícitos no sertão de Pernambuco e Piauí remontam ao início da década de 1980 (SANTOS et al., 1983).

O clima da região é marcado por uma longa estação seca e as chuvas são geralmente torrenciais (RIZZINI, 1997). Segundo dados pluviométricos mensais do Instituto Nacional de Meteorologia (período de 2006-2008), a precipitação média anual é inferior a $600 \mathrm{~mm}$, com chuvas concentradas no período de dezembro a março.

A área estudada faz parte do bioma Caatinga e apresenta as seguintes fitofisionomias (IBGE, 1992): Savana Estépica Florestada, Savana Estépica Arborizada, Savana Estépica Parque, Savana Estépica Gramíneo-Lenhosa e inclusões de Floresta Estacional (BRASIL, 2007). Ela abrange o Núcleo de desertificação Cabrobó e inclui os municípios de Cabrobó, Orocó, Santa Maria da Boa Vista, Belém de São Francisco e Floresta. 
Figura 1 - Mapa de localização da área de estudo no estado de Pernambuco.

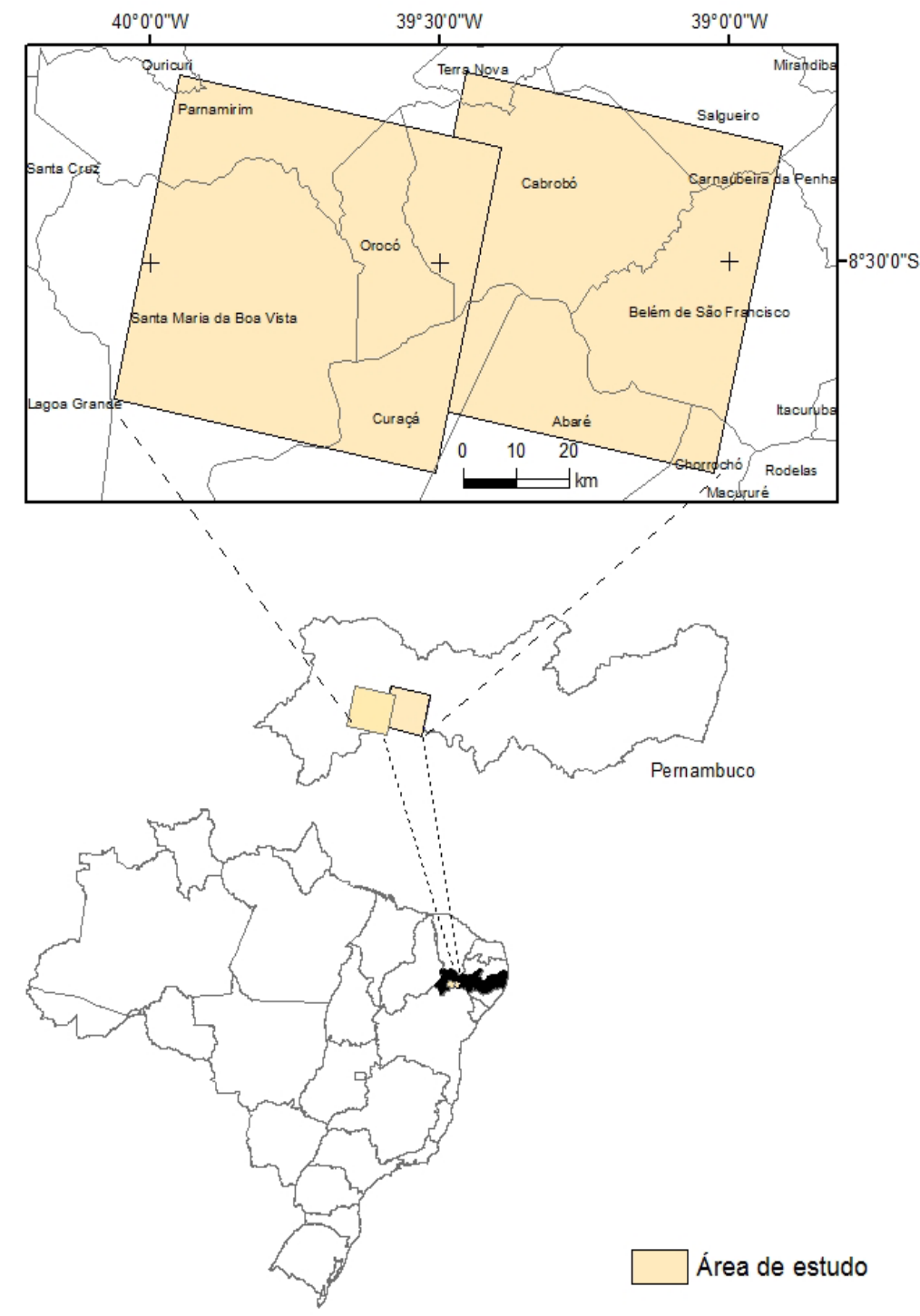

O núcleo Cabrobó foi definido em função do processo de desertificação regional, caracterizado pela degradação da Caatinga e pela consequente erosão e empobrecimento de solos, decorrentes principalmente do sobrepastejo, do desmatamento e da salinização do solo decorrente de projetos de irrigação em terras Bol. Ciênc. Geod., sec. Artigos, Curitiba, v. 19, no 1, p.45-64, jan-mar, 2013. 
inapropriadas, aliados ao contexto climático desfavorável (SÁ \& SÁ, 2008). Também tem sido relatado o estabelecimento de algumas espécies exóticas, propiciado pela degradação da vegetação natural, como é o caso da algarobeira nas planícies aluviais da Caatinga (NASCIMENTO, 2008). Em termos de uso de terras para fins comerciais, observa-se a presença de áreas de agricultura intensiva, concentradas sobretudo nas ilhas do rio São Francisco e nos projetos de fruticultura irrigada, assim como a criação extensiva de caprinos, ovinos e bovinos, principalmente em áreas ocupadas por pastagens nativas (formações gramíneolenhosas).

Geralmente as operações de plantio da Cannabis sativa incluem a limpeza do terreno, coveamento e plantio e implicam em remoção do estrato arbustivo e acumulação dos restos vegetais nos limites da lavoura. Durante os levantamentos de campo, constatou-se que a maioria dos plantios apresentava padrão uniforme, com espaçamentos regulares (principalmente $1 \mathrm{~m}$ x $1 \mathrm{~m}$ e $2 \mathrm{~m}$ × $2 \mathrm{~m}$ ), emprego de irrigação e fertilização. Geralmente são plantadas até oito plantas por cova e, quando adultas, são mantidas três a quatro plantas/cova. O estágio de crescimento dos exemplares de Cannabis sativa variou de pequenas plântulas a plantas maduras com até $2 \mathrm{~m}$ de altura (Figura 2).

Os tratos culturais contemplam o controle de plantas invasoras, mas também é comum a manutenção de exemplares arbóreos nativos com a finalidade de dissimular as roças e dificultar sua identificação pela Polícia. Os plantios são geralmente irrigados por gravidade ou por rega manual, sendo que, nas ilhas, a água para irrigação provém do rio São Francisco e, nos plantios localizados em terra firme, é utilizada água derivada de drenagens naturais perenes ou temporárias, canais de irrigação, açudes, lagoas, poços e/ou pequenos reservatórios de acumulação de água da chuva.

Com relação ao ciclo da cultura, entrevistas realizadas com policiais indicam que, na região, a planta atinge a maturidade em períodos que variam de quatro a seis meses. Esses dados são compatíveis com o constante na literatura (CLARKE, 1981; SOUZA et al., 2006), porém, há carência de experimentação controlada para obtenção de informações detalhadas sobre o desenvolvimento da planta na região de estudo.

\subsection{Dados de Campo}

Dados de localização de cultivos de Cannabis foram coletados durante operações de erradicação de plantios ilícitos executadas pela Polícia Federal nos períodos de 05 a 17 de junho de 2007, 21 a 26 de novembro de 2007 e 14 a 21 de maio de 2008, denominadas respectivamente de Operações Prometeu, Labareda e Colheita. Todas as campanhas de campo contaram com o apoio de helicópteros para localização dos plantios de Cannabis sativa. As coordenadas geográficas dos pontos visitados foram obtidas por meio de receptores GPS de navegação e foram omitidas neste trabalho por razões internas das instituições envolvidas. Os levantamentos de campo também incluíram a aquisição e registro de dados sobre as condições gerais 
do cultivo e adjacências tais como espaçamento de plantio e altura das plantas.

Figura 2 - Plantações de Cannabis sativa em estágios de crescimento correspondentes a plântulas (a), intermediário (b) e avançado (c). Fotos: Polícia Federal, obtidas em junho de 2007.

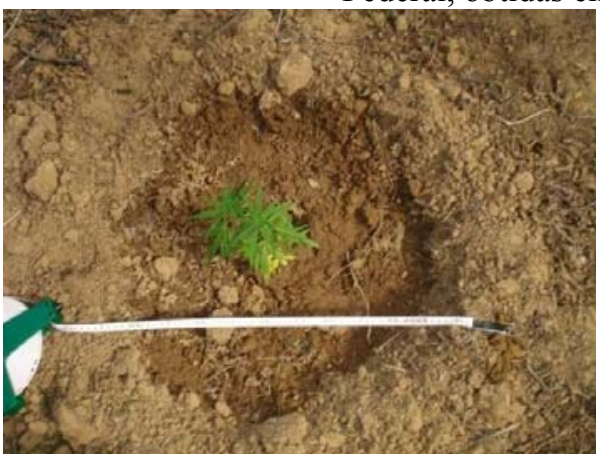

(a)

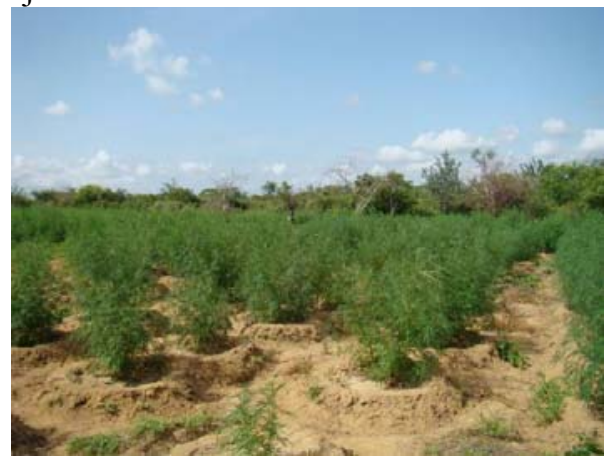

(b)

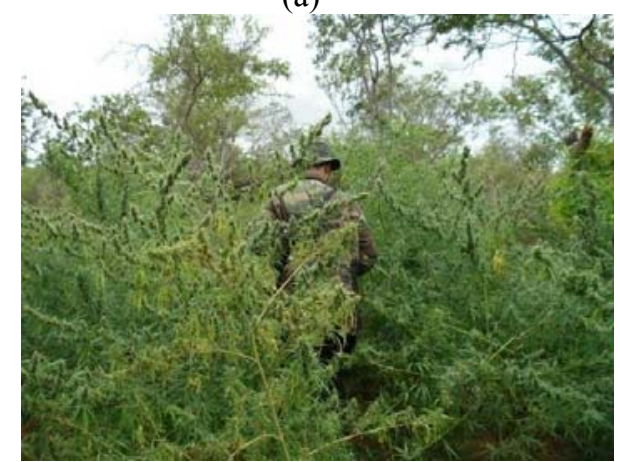

(c)

\subsection{Imagens do SPOT-5 HRG}

O conjunto de imagens de sensoriamento remoto utilizadas nesta pesquisa foi composto por cenas do satélite SPOT-5 HRG de maio/2006; setembro/2006; maio/2007; julho/2007; novembro/2007; e maio/2008 (Tabela 1). As cenas foram obtidas com os seguintes modos de imageamento: resolução espacial de $10 \mathrm{~m}$ no visível e no infravermelho próximo (bandas 1,2 e 3 , comprimentos de onda centrais de $0,540 \mu \mathrm{m}, 0,650 \mu \mathrm{m}$ e $0,830 \mu \mathrm{m}$, respectivamente) e $20 \mathrm{~m}$ na faixa do infravermelho de ondas curtas (banda 4, comprimento central de 1,630 $\mu \mathrm{m}$ ). 


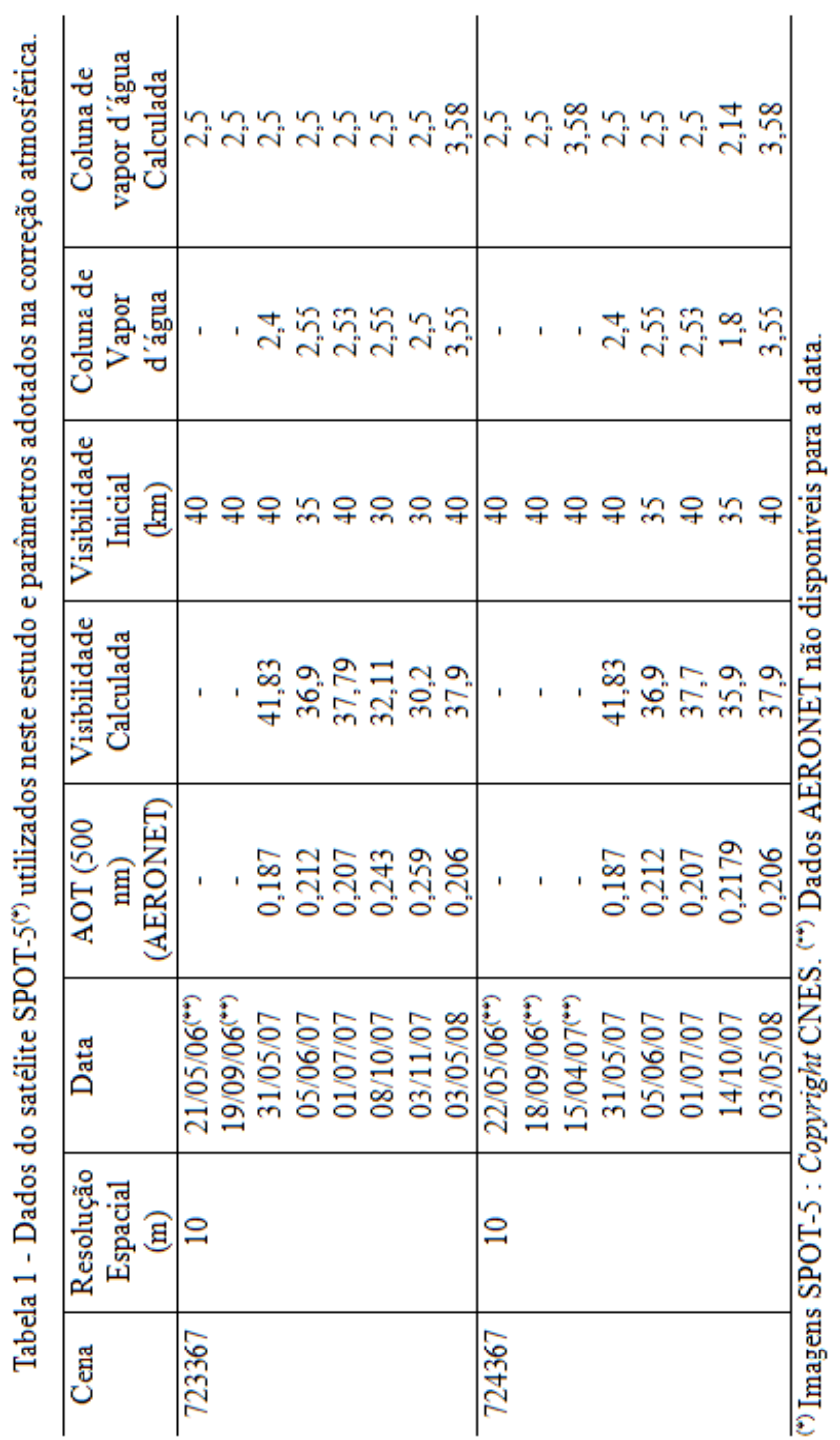

Essas imagens foram corregistradas, adotando-se, como referência geométrica, as cenas de julho de 2007. As datas de passagem foram selecionadas em função das programações de campo da Polícia Federal na área de estudo. As imagens foram processadas no nível 2A, que consiste na correção dos defeitos radiométricos 
provenientes de diferenças de sensibilidade entre os detectores individuais do sistema sensor e retificação das imagens para a projeção cartográfica padrão UTM WGS-84, sem pontos de apoio.

\subsection{Abordagem Metodológica}

Os dados SPOT-5 foram corrigidos para os efeitos da atmosfera com o intuito de possibilitar a generalização de parâmetros espectrais extraídos da imagem no espaço e no tempo (SONG et al., 2001; JENSEN, 2005; HOULES et al., 2006; SCHROEDER et al., 2006; EL HAJJ et al., 2008). Neste trabalho, foi aplicada a correção atmosférica absoluta das imagens SPOT-5 mediante o emprego do módulo FLAASH de correção atmosférica, disponível no aplicativo ENVITM (RSI, 2009). Detalhes da correção atmosférica aplicada nesse estudo podem ser encontrados em Lisita (2011).

A partir dos valores de reflectância da superfície, foram calculados os valores de NDVI do sensor multiespectral do satélite SPOT-5. A análise teve por objetivo comparar os valores absolutos e a variação temporal do NDVI dos sítios utilizados para o plantio ilícito de Cannabis sativa e da vegetação natural circundante e quantificar eventuais diferenças. Foram analisados os valores de NDVI correspondentes a dois sítios usados para o cultivo de Cannabis sativa e respectiva vegetação circundante em dados do SPOT-5 HRG obtidos nas estações chuvosa e seca. Os dados de campo foram coletados apenas durante as operações de erradicação dos referidos cultivos pela Polícia Federal em data discriminada nas análises temporais. A vegetação circundante a esses sítios é constituída por fitofisionomias da Caatinga, conforme detalhado nos estudos de caso apresentados a seguir.

\section{RESULTADOS}

A análise da dinâmica temporal do NDVI da cobertura vegetal natural e dos sítios de produção de Cannabis sativa indicou forte sazonalidade das fitofisionomias de Caatinga em contraposição aos padrões irregulares de variação dos plantios de Cannabis sativa, que apresentaram taxas de crescimento e tendências incompatíveis com as variações observadas na vegetação natural. Essas diferenças decorrem da irrigação e da adubação das plantas de Cannabis sativa, o que induz às taxas de crescimento muito superiores aos observados na vegetação natural em um mesmo período ou, também, à redução drástica da cobertura vegetal em ocasiões de preparo do solo ou colheita, correspondendo a quedas abruptas no NDVI.

Os resultados de dois estudos de caso da análise temporal do NDVI de plantios de Cannabis sativa e vegetação natural circundante são apresentados e discutidos a seguir. O primeiro exemplo corresponde a plantios de Cannabis sativa erradicados em 09 de junho de 2007 com área estimada de três hectares, 18.000 covas e 72.000 plantas com altura média de $1 \mathrm{~m}$ (Figuras 3 e 4). 
A análise dos NDVI nas datas amostradas indicou variações na Caatinga compatíveis com as variações sazonais, visto que, entre abril e maio, a área de Caatinga apresentou incremento sutil no NDVI, seguido por queda gradual no período de maio a julho, já demonstrando a redução do crescimento e indicando que o pico do NDVI ocorre no final da estação chuvosa. No mês de maio (final da estação chuvosa), os índices na Caatinga apresentaram-se elevados, registrando valores superiores a 0,8 , em oposição aos baixos índices observados na estação seca: em outubro de 2007, chegou a 0,27, indicando que o NDVI da Caatinga atinge valores mínimos no final da estação seca.

Por outro lado, o sítio de Cannabis sativa apresentou crescimento acentuado entre abril e maio de 2007, em função dos tratos culturais e irrigação seguido por queda súbita após a erradicação do plantio pela Polícia em junho de 2007. A variação do NDVI também foi analisada em termos relativos (Figura 5 e Tabela 2), ressaltando ainda mais a discrepância no padrão de crescimento dos sítios de Cannabis (Figura 6) em comparação à Caatinga. A variação temporal relativa do NDVI foi gerada por matemática de bandas conforme a equação: ((100*B2/B1) 100) onde B1 = NDVI em 15/04/2007 e B2 = NDVI em 31/05/2007.

Os dados demonstram que, enquanto os plantios de Cannabis sativa apresentaram incremento relativo do NDVI equivalente a $72 \%$ no período entre 15 de abril de 2007 e 31 de maio de 2007, as áreas cobertas com Caatinga Florestada mantiveram-se praticamente estáveis, com variação percentual de 1,85\%. A elevação brusca do NDVI indica vegetação em rápido crescimento que, no caso dos plantios de Cannabis sativa, é sustentado mesmo em condições desfavoráveis pela irrigação e demais práticas culturais geralmente empregadas nesse tipo de lavoura como a adição de corretivos e fertilizantes. Ao mesmo tempo, a variação do NDVI da Caatinga é pouco significativa e concomitante à queda da precipitação mensal, período que marca o seu pico vegetativo e o fim da estação de crescimento.

O segundo exemplo corresponde a três plantios de Cannabis sativa erradicados em 13 e 14 de junho de 2007 durante a Operação Prometeu. O plantio maior ocupava área estimada de 3,9 ha, 9.230 covas e 27.690 plantas de Cannabis sativa com altura variando entre $1 \mathrm{~m}$ a 1,6 m. Os outros dois plantios ocupavam área aproximada de 0,72 ha e 0,35 ha com, respectivamente, 2.129 covas e 8.516 plantas com altura entre 1,6 a $2 \mathrm{~m}$, e 1260 covas e plantas com altura entre 1,5 a $2 \mathrm{~m}$ (Figuras 7 a 9). 
Figura 3 - Sítio de produção ilegal de Cannabis sativa, circundado por Caatinga Florestada em série temporal do satélite SPOT-5 (composição colorida RGB 3/2/1, a

- g). Áreas de treinamento para medição do NDVI estão representadas por círculos pretos (Cannabis sativa - plantio ativo ou erradicado) e brancos (Caatinga Florestada). O plantio de Cannabis sativa foi erradicado durante a Operação Prometeu da Polícia Federal em 09 de junho de 2007.

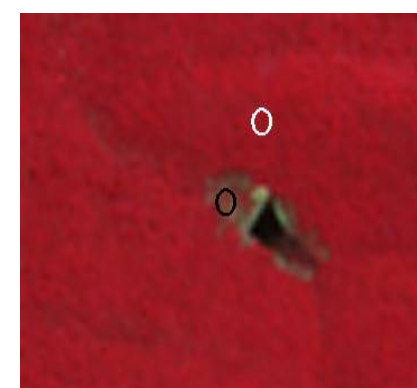

(a) $22 / 05 / 2006$

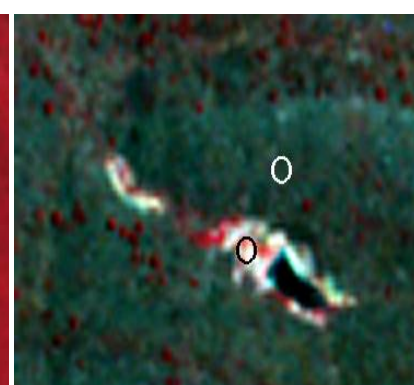

(b) $18 / 09 / 2006$

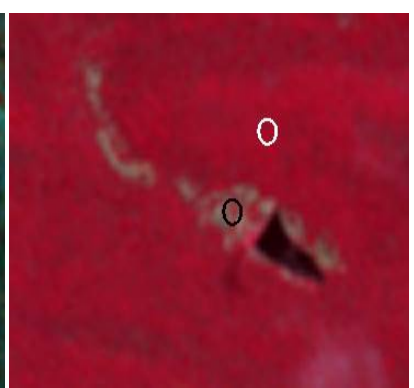

(c) $15 / 04 / 2007$

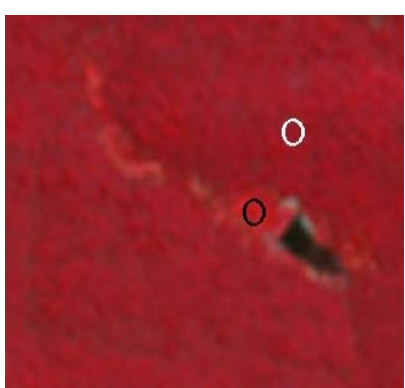

(d) $31 / 05 / 2007$

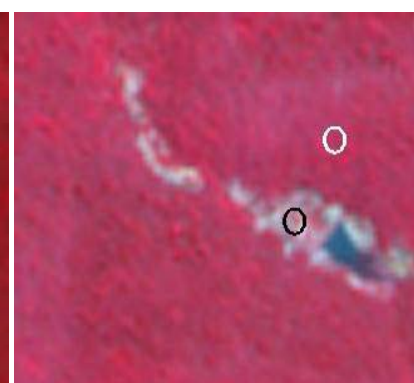

(e) $01 / 07 / 2007$

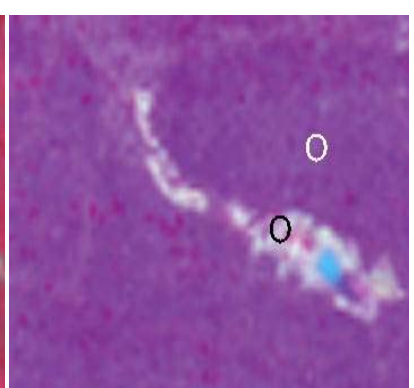

(f) $14 / 10 / 2007$

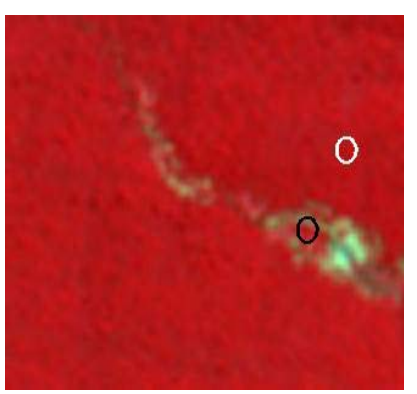

(g) $03 / 05 / 2008$ 


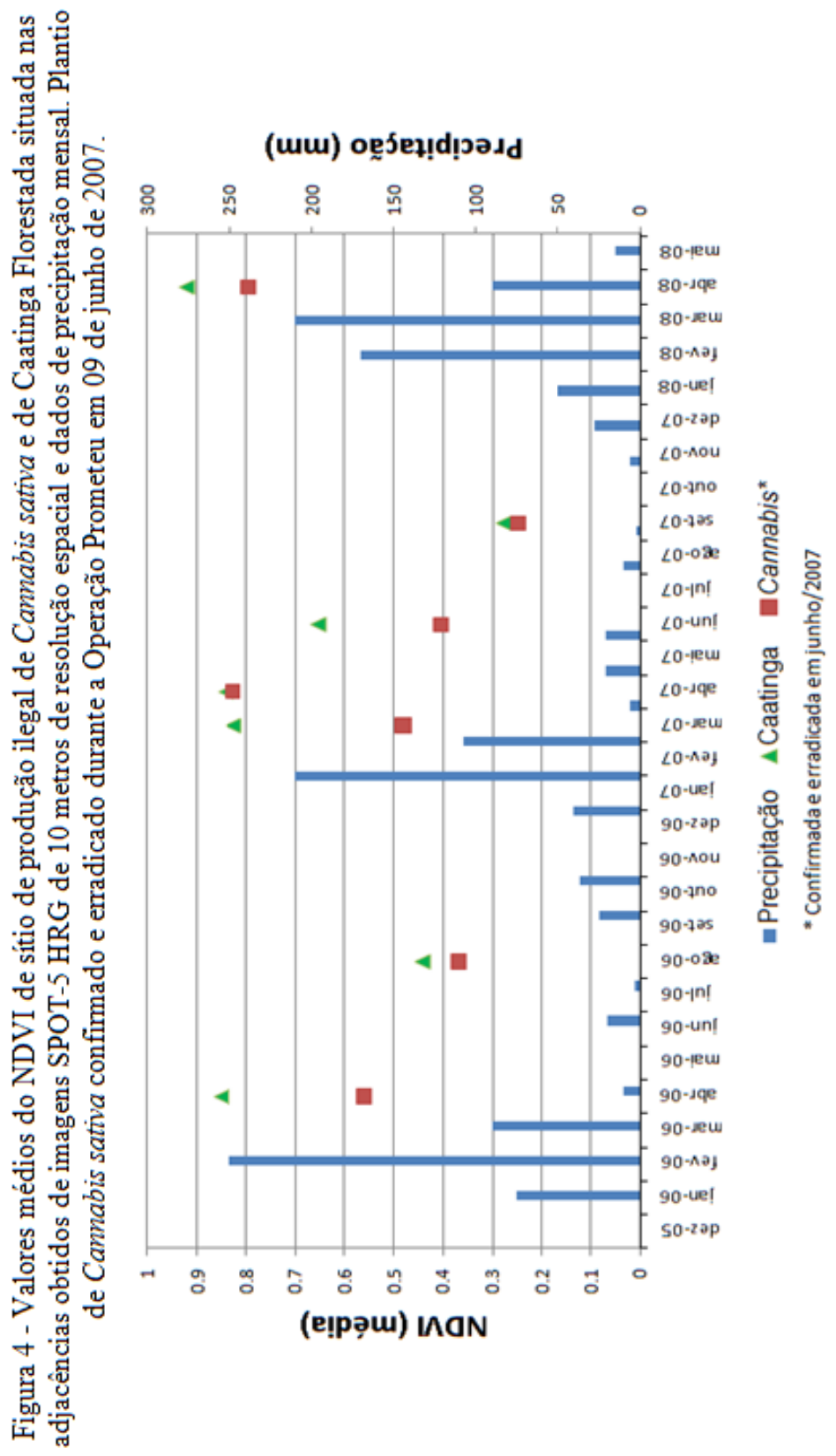

Bol. Ciênc. Geod., sec. Artigos, Curitiba, v. 19, no 1, p.45-64, jan-mar, 2013. 
Figura 5 - Sítio de produção ilegal de Cannabis sativa circundado por Caatinga Florestada em composição colorida SPOT-5 HRG (RGB 3/2/1) com 10 metros de resolução espacial e datas de passagem em 15 de abril de 2007 (a) e em 31 de maio de 2007 (b). Variação temporal relativa do NDVI gerada por matemática de bandas conforme a equação: $((100 * \mathrm{~B} 2 / \mathrm{B} 1)-100)$ onde B1 = NDVI em 15 de abril de 2007 e B2 = NDVI em 31 de maio de 2007 (c). Plantio de Cannabis sativa erradicado durante a Operação Prometeu em 9 de junho de 2007.

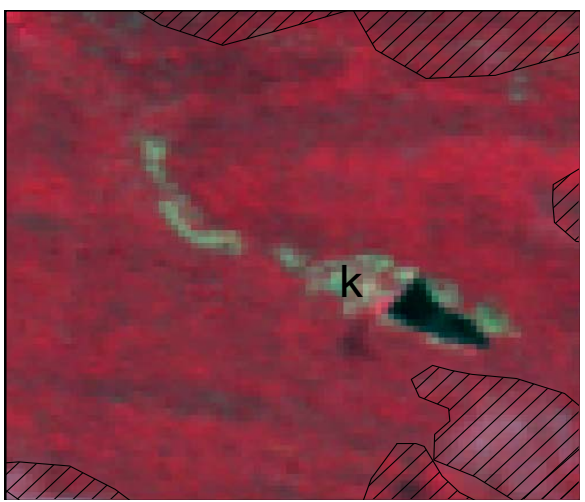

(a)

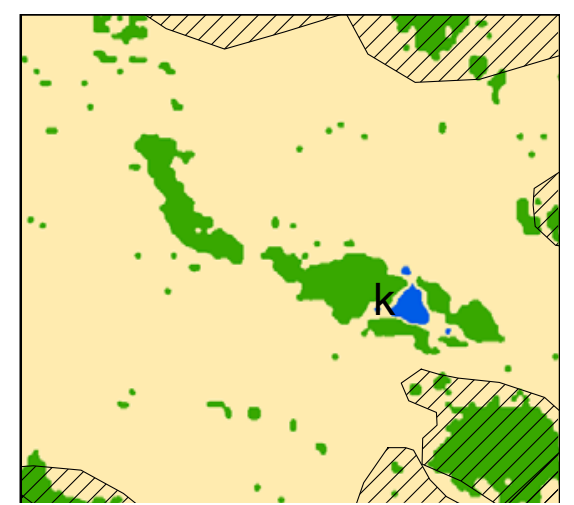

(c)

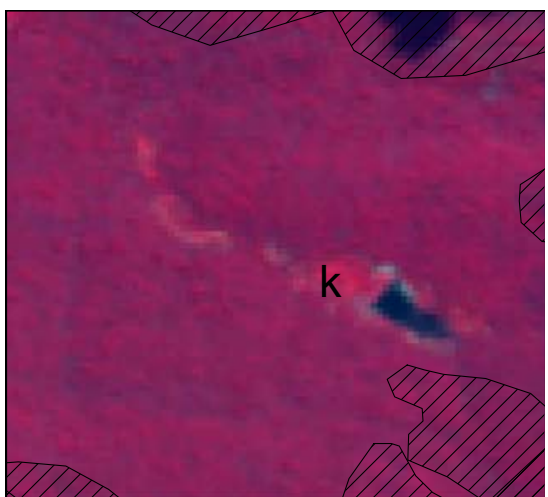

(b)

\section{Variação relativa do NDVI}

K Cannabis sativa Redução (-150 a -20\%) Estável (-20 a 10\%) Elevação (10 a 200\%)

P//A nuvens/sombra 
Tabela 2 - Valores médios e variação temporal relativa do NDVI de sítio ilegal de produção de Cannabis sativa e de Caatinga Florestada situada nas adjacências.

\begin{tabular}{|c|c|c|c|c|c|}
\hline Data & $\begin{array}{c}\text { NDVI } \\
\text { Cannabis }\end{array}$ & $\begin{array}{c}\text { NDVI } \\
\text { Caatinga } \\
\text { Florestada }\end{array}$ & Período & $\begin{array}{c}\text { Variação } \\
\text { NDVI } \\
\text { Cannabis } \\
(\%)\end{array}$ & $\begin{array}{c}\text { Variação } \\
\text { NDVI } \\
\text { Caatinga } \\
(\%) \\
\end{array}$ \\
\hline $22 / 05 / 2006$ & 0,559 & 0,850 & & & \\
\hline $18 / 09 / 2006$ & 0,369 & 0,442 & Maio/Setembro & $-34,04$ & $-47,97$ \\
\hline $15 / 04 / 2007$ & 0,481 & 0,826 & Setembro/Abril & 30,34 & 86,74 \\
\hline $31 / 05 / 2007$ & 0,827 & 0,841 & Abril-Maio & 72,02 & 1,86 \\
\hline $01 / 07 / 2007$ & 0,404 & 0,654 & Maio-Julho & $-51,22$ & $-22,29$ \\
\hline
\end{tabular}

Figura 6 - Fotos panorâmicas a partir de helicóptero do plantio registrado nas imagens SPOT-5. Fotos: Polícia Federal, obtida em junho de 2007.

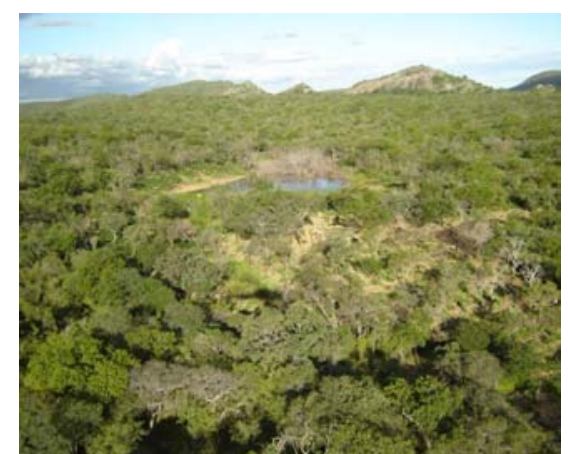

(a)

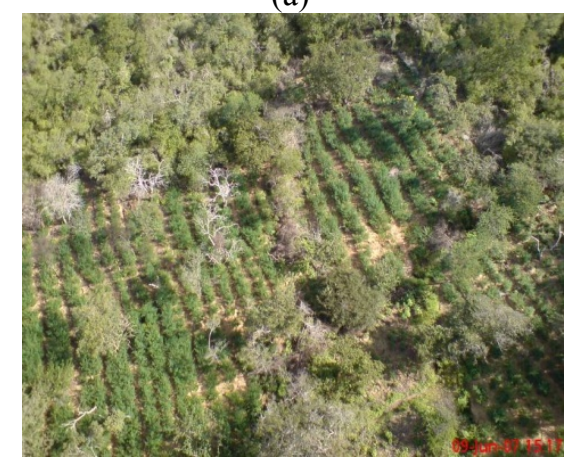

(c)

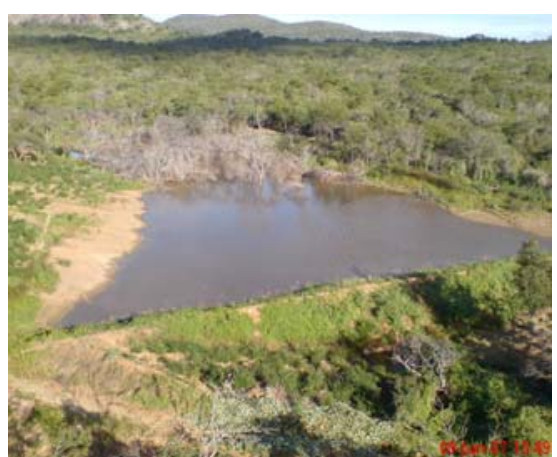

(b)

Bol. Ciênc. Geod., sec. Artigos, Curitiba, v. 19, nº 1, p.45-64, jan-mar, 2013. 
Figura 7 - Sítios de produção ilegal de Cannabis sativa circundados por vegetação ripária, mostrados em série temporal das imagens obtidas pelo satélite SPOT-5 (composição colorida RGB 3/2/1, a - f). Áreas de treinamento para medição do NDVI estão representadas por círculos pretos (Cannabis sativa - plantio ativo ou erradicado) e brancos (vegetação ripária). Plantios de Cannabis sativa confirmados e erradicados durante a Operação Prometeu em 13 e 14 de junho de 2007.

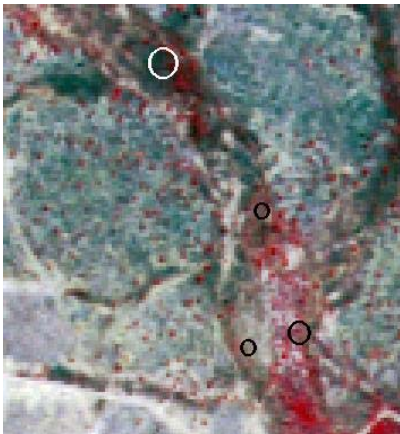

(a) $18 / 09 / 2006$

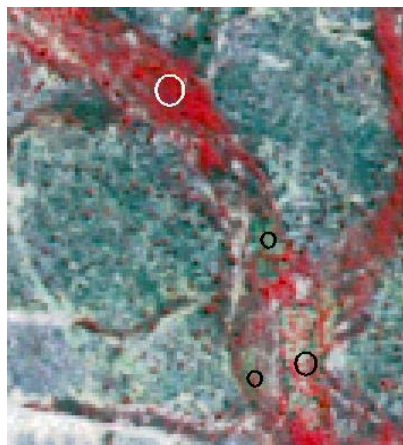

(d) $01 / 07 / 2007$

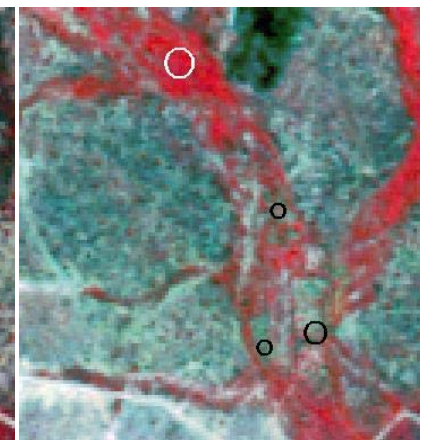

(b) $15 / 04 / 2007$

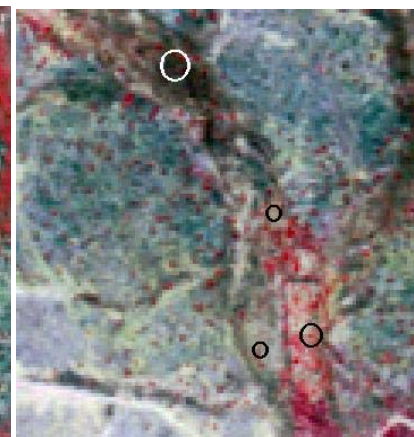

(e) $14 / 10 / 2007$

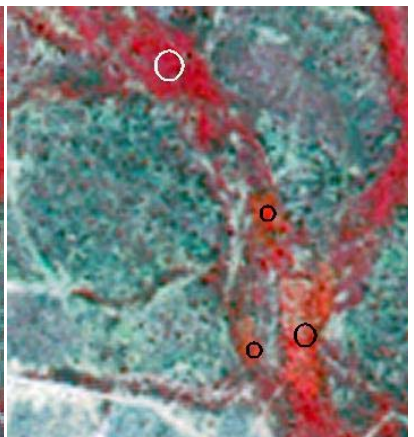

(c) $31 / 05 / 2007$

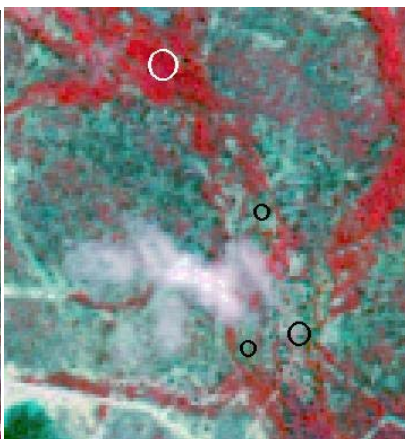

(f) $03 / 05 / 2008$ 


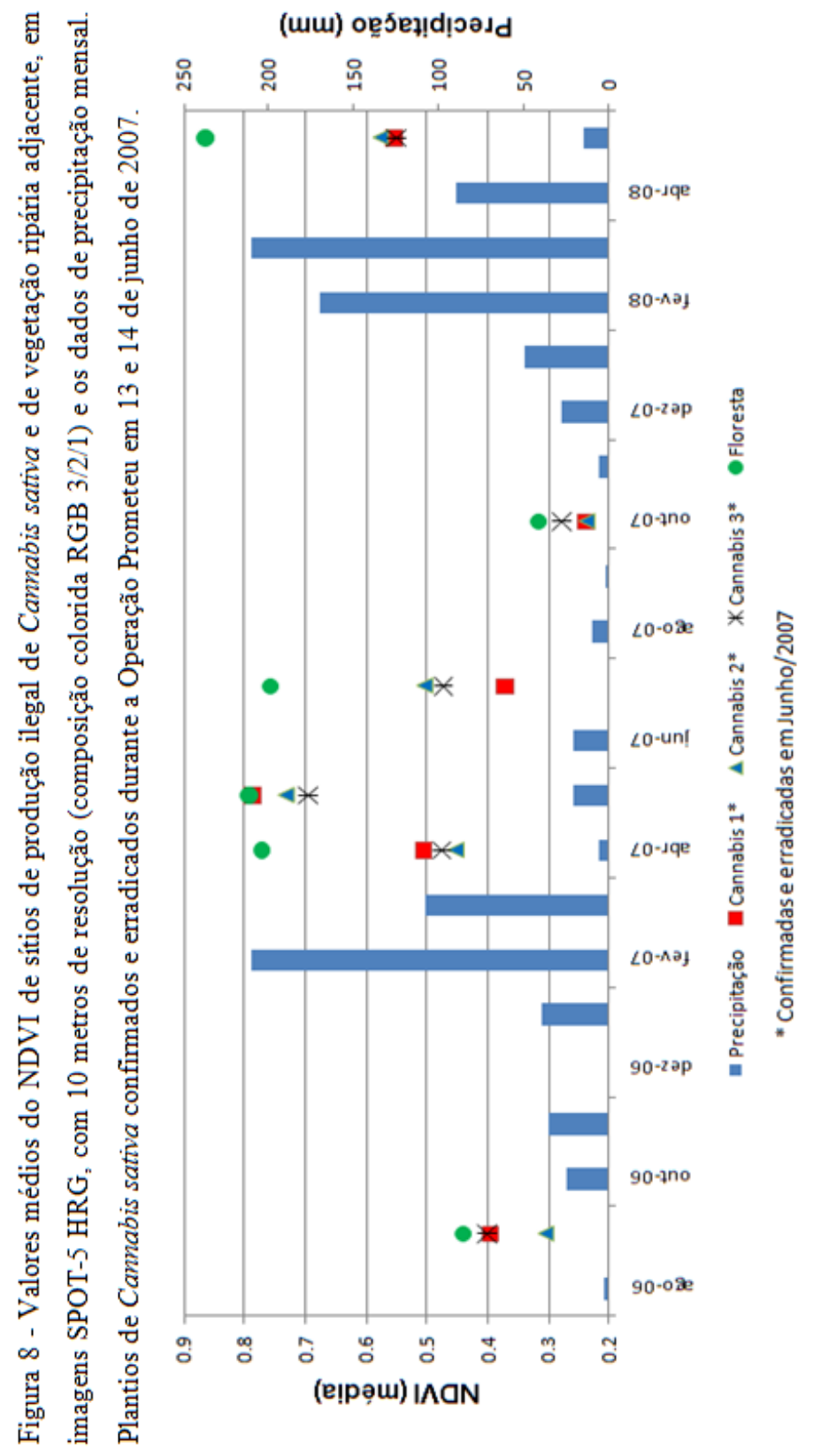

Bol. Ciênc. Geod., sec. Artigos, Curitiba, v. 19, no 1, p.45-64, jan-mar, 2013. 
Figura 9 - Sítios de produção ilegal de Cannabis sativa circundados por vegetação ripária em composição colorida SPOT-5 HRG, com 10 metros de resolução (composição colorida RGB 3/2/1) de 15 de abril de 2007 (a) e 31 de maio de 2007 (b). Variação temporal relativa do NDVI entre 15 de abril de 2007 e em 31 de maio de 2007 (c). Plantios confirmados e erradicados durante a Operação Prometeu em 13 e 14 de junho de 2007.

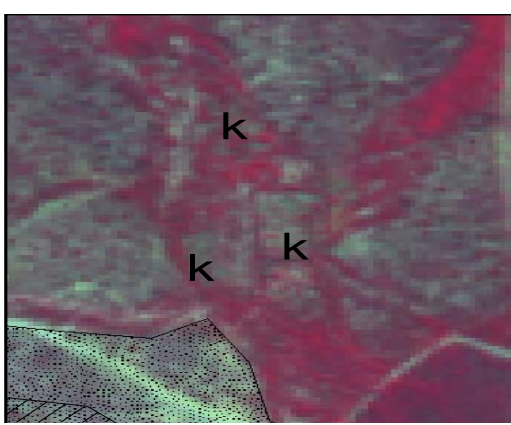

(a)

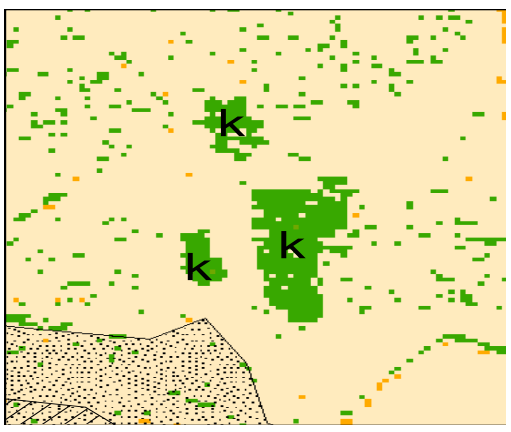

(c)

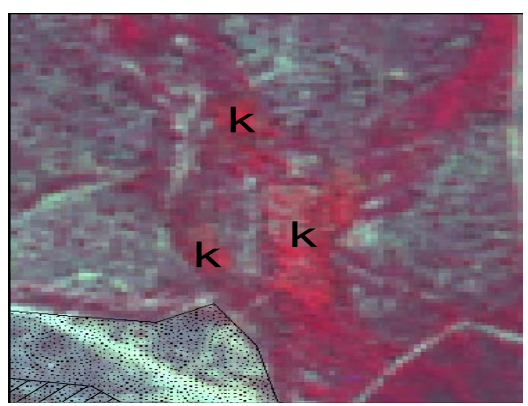

(b)

\section{Variação Relativa} do NDVI

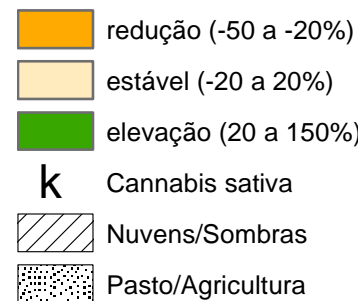

No segundo exemplo, a análise do NDVI nos meses de abril e maio de 2007 foi compatível com a tendência sazonal da Caatinga de apresentar pico vegetativo no final da estação chuvosa, seguido de queda gradual da biomassa com o início da estação seca. Os três sítios de produção de Cannabis cobertos pela imagem apresentaram crescimento vegetativo muito superior ao observado nas áreas de vegetação natural, e drástica queda entre maio e julho, após a erradicação do plantio pela Polícia em junho de 2007. Novamente, constatou-se valores de NDVI elevados para a vegetação natural nos meses de maio, final da estação chuvosa, com índices próximos a 0,8 , contra valores entre 0,3 e 0,4 em setembro de 2006 e abaixo de 0,3 em outubro de 2007. 
A variação relativa do NDVI no período resultou em incrementos entre $46 \%$ e $62 \%$ para os plantios de Cannabis sativa contra $2,72 \%$ na área de vegetação ripária adjacente, indicando o emprego de técnicas artificiais de cultivo nas áreas de Cannabis sativa em momento que ocorre a redução do crescimento da vegetação natural (Figura 9 e Tabela 3).

\begin{tabular}{|c|c|c|c|c|c|c|c|}
\hline \multirow{10}{*}{ 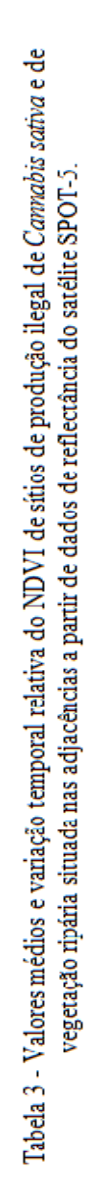 } & 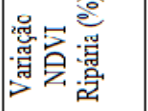 & & 蜩 & İ & $\stackrel{\text { f }}{+}$ & $\underset{\substack{g \\
i \\
i}}{g}$ & ఏ్ \\
\hline & 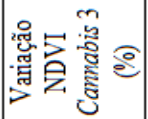 & & 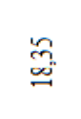 & "בু & 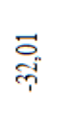 & $\begin{array}{l}\text { ż } \\
\overrightarrow{\neq}\end{array}$ & 学 \\
\hline & 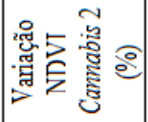 & & $\begin{array}{l}\tilde{c}^{2} \\
\text { on }\end{array}$ & E & 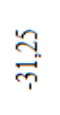 & $\begin{array}{l}\overrightarrow{7} \\
\text { तె }\end{array}$ & $\begin{array}{l}\stackrel{\circ}{2} \\
\text { 王 }\end{array}$ \\
\hline & 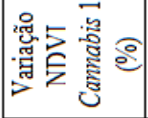 & & 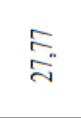 & 甯 & 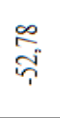 & 売 & Еే \\
\hline & 웜 & & 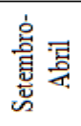 & 容递 & $\begin{array}{l}\text { 章 } \\
\text { 竞 } \\
\end{array}$ & 咅产 & 总열 \\
\hline & 点湋 & 啇 & $\underset{0}{E}$ & $\begin{array}{l}\text { హ్ } \\
\text { ○. }\end{array}$ & 点 & ㅎ․ & 岕 \\
\hline & 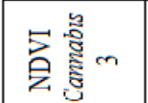 & 察 & 朵 & 哭 & 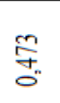 & శิ & 合 \\
\hline & 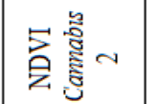 & के. & $\overrightarrow{\overrightarrow{7}}$ & 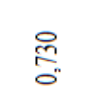 & 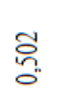 & 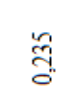 & 答 \\
\hline & 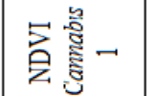 & 命 & 总 & 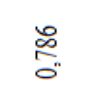 & 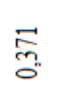 & ন্ & 萦 \\
\hline & 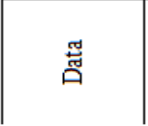 & 享 & $\begin{array}{l}\text { 㐔 } \\
\text { 产 } \\
\text { : }\end{array}$ & $\begin{array}{l}\text { 今े } \\
\text { 言 } \\
\text { ले }\end{array}$ & 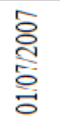 & 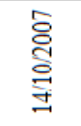 & 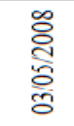 \\
\hline
\end{tabular}

\section{CONCLUSÕES}

Nos exemplos analisados, a vegetação natural apresentou padrões sazonais de elevação do NDVI no final da estação chuvosa e queda durante a estação seca, com pequenas variações interanuais nos índices registrados. Contrariamente, observou-se 
comportamento bastante irregular dos plantios de Cannabis sativa, com incrementos ou quedas bruscas do NDVI decorrentes, respectivamente, de períodos de rápido crescimento sustentado artificialmente com emprego de irrigação ou da remoção do estrato vegetal durante colheitas pelos plantadores ou erradicações pela polícia. $\mathrm{O}$ uso do contraste do NDVI em séries temporais do satélite SPOT-5 por meio de imagens de diferença demonstrou que a análise de mudanças pode contribuir para a detecção de cultivos de Cannabis sativa em áreas de vegetação natural vulneráveis à instalação de plantios ilícitos.

\section{AGRADECIMENTOS:}

Esta pesquisa foi patrocinada pela Polícia Federal por meio da Diretoria Técnico-Científica e da Diretoria de Combate ao Crime Organizado. Os autores agradecem o acesso sem custo aos dados SPOT-5, disponibilizados pelo Programa SEAS-Guyane do Institut de Recherche pour le Développement (IRD) por meio da Unidade de pesquisa ESPACE-DEV em Caiena - Guiana Francesa. As Nações Unidas contra a Droga e o Crime (Escritório do Brasil e Cone Sul) e a FINEP (Financiadora de Estudos e Projetos) também prestaram suporte financeiro a esta pesquisa. Agradecemos também ao Dr. Ênio B. Pereira pela sua contribuição em estabelecer e manter a sonda Petrolina da rede AERONET publicada pela NASA GSFC.

\section{REFERÊNCIAS BIBLIOGRÁFICAS}

BRASIL - MINISTERIO DO MEIO AMBIENTE. Edital Probio 02/2004. Projeto executivo B.02.02.109. Mapeamento de cobertura vegetal do bioma Caatinga: relatório final. Brasília, DF, 2007. Projeto concluído. Coordenador técnico: Washington Rocha. Unidades executoras: Universidade Federal de Feira de Santana, Embrapa Semiárido. Disponível em: <http://mapas.mma.gov.br/ geodados/brasil/vegetacao/vegetacao2002/caatinga/documentos/relatorio_final.p df $>$. Acesso em: 16 mar. 2009.

CAMILO, A. A.; COSTA FILHO, J. F.; SÁ, T. F. F.; BRAGA JUNIOR, J. M. Resposta espectral da cana-de-açúcar irrigada no município de Quixeré no Ceará. In: Simpósio Brasileiro de Ciências Geodésicas e Tecnologias da Geoinformação, 3. Recife, PE, 27-30 de julho de 2010. Anais... Rio de Janeiro: ABEC, 2010, p. 1-9.

CLARKE, R. C. Marijuana Botany. An Advanced Study. The propagation and breeding of distinctive Cannabis. Oakland: Ronin Publishing, 1981. 220 p.

DAUGHTRY, C. S. T. L.; WALTHALL, C. Spectral discrimination of Cannabis sativa L. leaves and canopies. Remote Sensing of Environment, v. 64, p. $192-$ 201, 1998.

EL HAJJ, M. ; BEGUE, A. ; LAFRANCE, B. ; HAGOllE, O. ; DEDIEU, G.; RUMEAU, M. Relative radiometric normalization and atmospheric correction of a SPOT-5 time series. Sensors, v. 8, n. 4, p. 2774-2791, 2008. 
HOULES, V.; EL HAJJ, M.; BEGUE, A. Radiometric normalization of a SPOT-4 and SPOT-5 time series of images (Isle-Reunion) for agriculture applications. Revue Française de Photogrammetrie et de Teledetection, v. 181, 2006. p. 3137.

IBGE. Instituto Brasileiro de Geografia e Estatística. Manual Técnico da Vegetação Brasileira. Rio de Janeiro: IBGE, 1992, 92 p. (Manuais Técnicos em Geociências, 1.).

JENSEN, J. R. Introductory digital image processing. A remote sensing perspective, Upper Saddle River: Prentice Hall, 2005. 526 p.

LISITA, A. Mapeamento semiautomático de cultivos ilícitos de Cannabis sativa no semiárido Pernambucano mediante integração de imagens SPOT-5 - HRG, dados geográficos auxiliares e conhecimento de campo. Tese (Doutorado em Geociências Aplicadas) Brasília, Universidade de Brasília, 2011, 210 p.

NASCIMENTO, C. E. S. Comportamento invasor da algarobeira Prosopis juliflora (sw) dc. nas planícies aluviais da Caatinga. Tese (Doutorado em Biologia Vegetal) - Universidade Federal de Pernambuco, Programa de Pós-Graduação, Recife, 2008. 115 p.

PONZONI, F. J.; SHIMABUKURO, Y. E. Sensoriamento remoto no estudo da vegetação. São José dos Campos: Editora Parêntese, 2007. 144 p.

RATANA, P.; HUETE, A. R.; FERREIRA, L. Analysis of Cerrado physiognomies and conversion in the MODIS seasonal-temporal domain. Earth Interactions, v. 9, Paper 3, 2005. 22 p.

RIZZINI, C. T. Tratado de fitogeografia do Brasil. Aspectos ecológicos, sociológicos e florísticos. Rio de Janeiro: Âmbito Cultural Edições, 1997. 747 p.

RSI. Research Systems Inc. ENVI User's Guide. ENVI Version 4.7. Research Systems Inc, 2009.

SÁ, I. B.; SÁ, I. I. S. A cobertura vegetal do bioma Caatinga: subsídios ao monitoramento de processos de desertificação. In: Seminário de Atualização Em Sensoriamento Remoto e Sistemas de Informações Geográficas Aplicados à Engenharia Florestal, 8., Curitiba, 7 a 9 de outubro de 2008. Anais... Manaus: FAPEAM, 2008. p. 677-686.

SANTOS, A. P. ; CREPANI, E. ; SANTOS, J. R. ; MARTINI, P. R. ; NOVAES, R. A. Mapeamento de áreas plantadas com Cannabis sativa através de transparências coloridas infravermelhas. São José dos Campos: INPE, 1983. 29 p. Disponível em: <http://marte.dpi.inpe.br/col/dpi.inpe.br/marte@80/2009/ 04.13.12.56/doc/506-515.pdf>. Acesso em: 15 mar. 2011.

SCHROEDER, T. A.; COHEN, W. B.; SONG, C.; CANTY, M. J.; YANG, Z. Radiometric correction of multi-temporal Landsat data for characterization of early successional forest patterns in western Oregon. Remote Sensing of Environment, v. 103, p. 16-26, 2006.

SONG, C.; WOODCOCK, C. E.; SETO, K. C.; LENNEY, M. P.; MACOMBER, S. A. Classification and change detection using Landsat TM data: when and how to 
correct atmospheric effects? Remote Sensing of Environment, v. 75, n. 2, p. 230244,2001

SOUZA, D. Z.; MICHELIN, K.; HOLLER, M. G.; SOARES, G. L. G.; RITTER, M. R.; BIANCHI, N. R. Roteiro ilustrado para identificação morfológica de Cannabis sativa L. Perícia Federal, n. 24, p. 16-22, 2006.

TUCKER, C. J. Red and photographic infrared linear combinations for monitoring vegetation. Remote Sensing of Environment, v. 8, p. 127-150, 1979.

UNODC. Escritório das Nações Unidas sobre Drogas e Crime. World drug report 2008. 2008. Disponível em: <http://www.unodc.org/documents/wdr/WDR_2008 /WDR 2008 eng_web.pdf $>$. Acesso em: 6 mar. 2009.

WALTHALL, C.; DAUGHTRY, C.; LYDON, J. Detection of illegal Cannabis cultivation using remote sensing. In: International Geoscience and Remote Sensing Symposium (IGARSS 2006), Denver, Colorado, 31 julho a 4 de agosto de 2006. Proceedings... 2006, p. 2281-2285.

(Recebido em outubro de 2012. Aceito em dezembro de 2012). 